\title{
Serum corin is associated with the risk of chronic heart failure
}

\author{
Zongliang $\mathrm{Yu}^{1, *}$, Xiang $\mathrm{Lu}^{2, *}$, Weiting $\mathrm{Xu}^{3,{ }^{3}}$, Mengchao $\mathrm{Jin}^{3}$, Yifei $\mathrm{TaO}^{3}$ and $\mathrm{Xiang}$ \\ Zhou ${ }^{3}$ \\ ${ }^{1}$ Department of Cardiology, The First People's Hospital of Kunshan Affiliated to Jiangsu University, Kunshan, China \\ ${ }^{2}$ Department of Geriatrics, Sir Run Run Hospital, Nanjing Medical University, Nanjing, China \\ ${ }^{3}$ Department of Cardiology, The Second Affiliated Hospital of Soochow University, Suzhou, China \\ *These authors have contributed equally to this work
}

Correspondence to: Xiang Zhou, email: zhou-xiang@suda.edu.cn

Keywords: chronic heart failure; corin; risk

Received: August 16, $2017 \quad$ Accepted: October 13, $2017 \quad$ Published: November 01, 2017

Copyright: Yu et al. This is an open-access article distributed under the terms of the Creative Commons Attribution License 3.0 (CC BY 3.0), which permits unrestricted use, distribution, and reproduction in any medium, provided the original author and source are credited.

\section{ABSTRACT}

It has been well documented that corin is a critical protease involved in the regulation of blood pressure and cardiac function. We performed a case-control study to determine whether serum corin is associated with the risk of chronic heart failure (CHF). We included 484 consecutive CHF patients and 484 control subjects to investigate the potential relationship between serum corin and $\mathrm{CHF}$ using logistic regression analysis. Compared with healthy controls, the CHF patients were more likely to have histories of hypertension and diabetes, and had higher levels of $\mathbf{N}$-terminal pro-brain natriuretic peptide and lower levels of corin. The odds ratios of ischemic and non-ischemic HF were significantly reduced with the growing levels of serum corin after multivariate adjustment. Moreover, the decrease in serum corin levels seemed to be associated with the severity of CHF. In conclusion, our study suggested that serum corin levels were reduced in CHF patients and inversely correlated with the incidence of ischemic and non-ischemic HF.

\section{INTRODUCTION}

Corin is known as a transmembrane serine protease and has multiple physiological functions in the cardiovascular system. This protease mainly exists in myocardial cells and plays crucial roles in processing pronatriuretic peptides, thereby regulating salt-water balance and vasodilation [1]. Recently, increasing evidence has indicated that corin is actively involved in the modulation of blood pressure and cardiac function. It was reported that corin knockout eventually resulted in spontaneous hypertension and myocardial dysfunction in mice [2]. On the contrary, overexpression of corin was found to improve cardiac function and survival in mice with dilated cardiomyopathy [3]. Moreover, in population-based epidemiological studies, serum corin levels were found to be decreased in patients with acute myocardial infarction and stoke $[4,5]$.
Chronic heart failure (CHF), a clinical syndrome characterized by reduced myocardial contractility, hemodynamic abnormality and neuroendocrine activation, is the major cause of mortality and morbidity in patients with cardiovascular diseases [6]. Over the past few years, numerous risk factors have been identified to be associated with the development of CHF. In the present study, we carried out a hospital-based case-control study to investigate the potential relationship between serum corin and CHF risk.

\section{RESULTS}

In this study, there were 484 control subjects and 484 CHF patients, including 235 coronary heart disease, 97 valvular heart disease, 83 hypertensive heart disease, 42 dilated cardiomyopathy and 27 other cardiovascular diseases. The baseline characteristics of the study 
Table 1: Baseline characteristics of CHF patients and controls

\begin{tabular}{lccc}
\hline & $\begin{array}{c}\text { Control } \\
(\mathbf{n = 4 8 4})\end{array}$ & $\begin{array}{c}\text { CHF } \\
(\mathbf{n = 4 8 4})\end{array}$ & P value \\
\hline Age (years) & $62.8 \pm 7.4$ & $64.5 \pm 8.3$ & NS \\
Male (\%) & $292(60.3)$ & $306(63.2)$ & $<0.001$ \\
Hypertension (\%) & $216(44.6)$ & $278(57.4)$ & $<0.001$ \\
Diabetes (\%) & $90(18.6)$ & $142(29.3)$ & NS \\
Hyperlipidemia $(\%)$ & $207(42.8)$ & $221(45.7)$ & NS \\
Smoking $(\%)$ & $185(38.2)$ & $203(41.9)$ & $<0.001$ \\
eGFR $\left(\mathrm{ml} / \mathrm{min} / 1.73 \mathrm{~m}^{2}\right)$ & $89.4 \pm 8.3$ & $67.8 \pm 10.2$ & $<0.001$ \\
NT-proBNP $(\mathrm{pg} / \mathrm{ml})$ & $271 \pm 35$ & $3054 \pm 420$ & $<0.001$ \\
Corin $(\mathrm{pg} / \mathrm{ml})$ & $1182 \pm 237$ & $763 \pm 175$ & \\
\hline
\end{tabular}

Data are expressed as mean $\pm \mathrm{SD}$ or numbers (percentage). $\mathrm{CHF}=$ chronic heart failure; eGFR = estimated glomerular filtration rate; NT-proBNP $=\mathrm{N}$-terminal pro-brain natriuretic peptide.

Table 2: Characteristics of patients subdivided by ischemic and non-ischemic HF

\begin{tabular}{lccc}
\hline & $\begin{array}{c}\text { Ischemic } \\
(\mathbf{n = 2 3 5 )}\end{array}$ & $\begin{array}{c}\text { Non-ischemic } \\
(\mathbf{n}=\mathbf{2 4 9})\end{array}$ & P value \\
\hline Age (years) & $68.2 \pm 7.6$ & $61.0 \pm 8.9$ & $<0.001$ \\
Male (\%) & $165(70.2)$ & $141(56.6)$ & $<0.001$ \\
Hypertension (\%) & $153(65.1)$ & $125(50.2)$ & $<0.001$ \\
Diabetes (\%) & $82(34.9)$ & $60(24.1)$ & $<0.001$ \\
Hyperlipidemia (\%) & $125(53.2)$ & $96(38.6)$ & $<0.001$ \\
Smoking $(\%)$ & $110(46.8)$ & $93(37.3)$ & $<0.001$ \\
eGFR (ml/min/1.73 m $\left.{ }^{2}\right)$ & $70.3 \pm 9.8$ & $65.4 \pm 10.7$ & NS \\
NT-proBNP $(\mathrm{pg} / \mathrm{ml})$ & $2936 \pm 395$ & $3165 \pm 452$ & NS \\
Corin $(\mathrm{pg} / \mathrm{ml})$ & $809 \pm 194$ & $720 \pm 158$ & NS \\
\hline
\end{tabular}

Data are expressed as mean $\pm \mathrm{SD}$ or numbers (percentage). $\mathrm{HF}=$ heart failure; eGFR = estimated glomerular filtration rate; NT-proBNP $=$ N-terminal pro-brain natriuretic peptide.

Table 3: Association of serum corin with $\mathrm{CHF}$

\begin{tabular}{lccc}
\hline Corin (quartiles) & $\begin{array}{c}\text { Control } \\
(\mathbf{n = 4 8 4 )}\end{array}$ & $\begin{array}{c}\text { CHF } \\
(\mathbf{n = 4 8 4 )}\end{array}$ & $\begin{array}{c}\text { Adjusted OR* } \\
(\mathbf{9 5 \%} \text { CI) }\end{array}$ \\
\hline Q1 $(<813 \mathrm{pg} / \mathrm{ml})$ & 121 & 186 & 1.00 \\
Q2 $(813-1129 \mathrm{pg} / \mathrm{ml})$ & 121 & 150 & $0.83(0.59-1.12)$ \\
Q3 $(1129-1378 \mathrm{pg} / \mathrm{ml})$ & 121 & 97 & $0.56(0.37-0.85)$ \\
Q4 $(>1378 \mathrm{pg} / \mathrm{ml})$ & 121 & 51 & $0.31(0.18-0.64)$ \\
$P$ for trend & & & $<0.001$ \\
\hline
\end{tabular}

*Adjustment for hypertension, diabetes, eGFR and NT-proBNP in analysis. $\mathrm{CHF}=$ chronic heart failure; OR = odds ratio; $\mathrm{CI}=$ confidence interval. 
Table 4: Association of serum corin with ischemic and non-ischemic HF

\begin{tabular}{lccccc}
\hline \multirow{2}{*}{ Corin (quartiles) } & \multicolumn{2}{c}{ Ischemic $(\mathbf{n}=\mathbf{2 3 5})$} & & \multicolumn{2}{c}{ Non-ischemic (n= 249) } \\
\cline { 2 - 3 } \cline { 5 - 6 } & Case/control & $\begin{array}{c}\text { Adjusted OR } \\
(\mathbf{9 5 \%} \text { CI) }\end{array}$ & & Case/control & $\begin{array}{c}\text { Adjusted OR* } \\
\text { (95\% CI) }\end{array}$ \\
\hline Q1 $(<813 \mathrm{pg} / \mathrm{ml})$ & $86 / 121$ & 1.00 & & $100 / 121$ & 1.00 \\
Q2 $(813-1129 \mathrm{pg} / \mathrm{ml})$ & $72 / 121$ & $0.86(0.57-1.23)$ & & $78 / 121$ & $0.80(0.61-1.09)$ \\
Q3 $(1129-1378 \mathrm{pg} / \mathrm{ml})$ & $48 / 121$ & $0.59(0.34-0.92)$ & & $49 / 121$ & $0.52(0.29-0.83)$ \\
Q4 $(>1378 \mathrm{pg} / \mathrm{ml})$ & $29 / 121$ & $0.37(0.20-0.71)$ & & $22 / 121$ & $0.26(0.15-0.58)$ \\
$P$ for trend & & $<0.001$ & & & $<0.001$ \\
\hline
\end{tabular}

*Adjustment for hypertension, diabetes, eGFR and NT-proBNP in analysis. HF = heart failure; $\mathrm{OR}=$ odds ratio; $\mathrm{CI}=$ confidence interval.

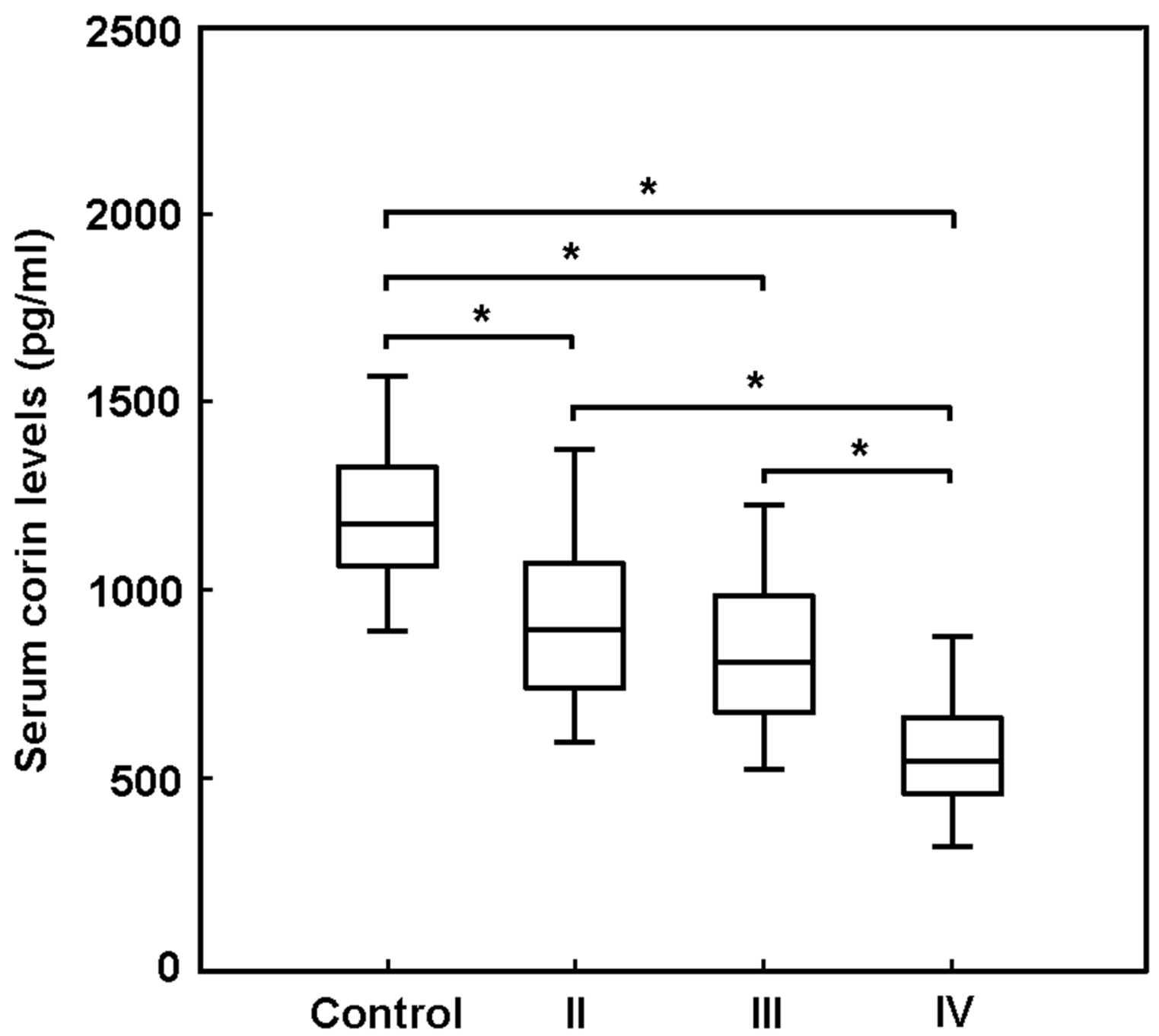

Figure 1: The cardiac function in patients with chronic heart failure (CHF) was divided into 4 groups according to the NYHA classification. The serum levels of corin were progressively lower in CHF patients with more severe cardiac dysfunction. ${ }^{*} \mathrm{P}<0.05$. 
population are shown in Tables 1 and 2. The serum levels of corin were significantly decreased in $\mathrm{CHF}$ patients compared with those in the controls. The CHF patients were more likely to have histories of hypertension and diabetes, and had lower eGFR and higher NT-proBNP levels. In addition, the $\mathrm{CHF}$ patients were divided into 2 groups according to myocardial ischemia. Patients with ischemic HF tended to be male and older, and were more likely to have histories of hypertension, diabetes, hyperlipidemia and smoking.

Participants were divided into quartiles of corin levels in control subjects to assess the association between serum corin and $\mathrm{CHF}$. With the lowest quartile as a reference, the ORs of CHF were calculated and the results are presented in Table 3. Our findings indicated that CHF was significantly correlated with reduced levels of corin $(P$ for trend, $<0.001)$ after adjusting for hypertension, diabetes, eGFR and NT-proBNP.

As shown in Table 4, both ischemic and nonischemic HF were associated with the decreasing levels of serum corin after multivariate adjustment ( $\mathrm{P}$ for trend, $<0.001)$. Participants in the highest quartile had $0.37 \times$ (OR, 0.37; 95\% CI, 0.20-0.71) the OR of ischemic HF and $0.26 \times(\mathrm{OR}, 0.26 ; 95 \% \mathrm{CI}, 0.15-0.58)$ the OR of nonischemic HF for participants in the lowest quartile.

Our findings revealed that the decrease in serum corin levels seemed to be associated with the severity of CHF. The cardiac function in CHF patients was divided into 4 groups according to the NYHA classification. As shown in Figure 1, the serum levels of corin were progressively lower in CHF patients with more severe cardiac dysfunction.

\section{DISCUSSION}

We carried out this case-control study to determine the association of serum corin with $\mathrm{CHF}$ risk in a Chinese population. Our results showed that serum levels of corin were significantly decreased in CHF patients. The ORs of ischemic and non-ischemic HF were markedly reduced with the growing levels of serum corin following multivariate adjustment, which suggests that serum corin was inversely correlated with the incidence of $\mathrm{CHF}$.

Corin, which belongs to the transmembrane serine protease family, has a cytoplasmic tail and a singlespan transmembrane domain near the N-terminus [7]. Accumulating evidence has demonstrated that corin is involved in the regulation of blood pressure and cardiac function by activating natriuretic peptides. Under the conditions of volume or pressure overload, there is increased production of natriuretic peptides in the heart, which consequently induces diuresis and vasodilation [8]. Recent studies by Zhou et al. have revealed that corin is a valuable prognostic marker of major adverse cardiovascular events in patients with $\mathrm{CHF}$ and acute myocardial infarction, independent of conventional risk factors $[9,10]$. In the present study, serum corin levels were found to be reduced in CHF patients, which was in accordance with the results of a previous study [11]. In addition, our findings also indicated that serum corin was inversely associated with the incidence of ischemic and non-ischemic HF. Furthermore, serum corin levels were progressively lower in CHF patients with more severe cardiac dysfunction.

This study has several limitations. Firstly, it remains unknown whether reduced corin is the cause or the result of $\mathrm{CHF}$, so the conclusions need to be further verified in prospective cohort studies. Secondly, this study was conducted in a Chinese population and the conclusions should be cautiously extrapolated to other ethnic groups. Thirdly, we cannot avoid selection bias, information bias and confounding bias in this study.

In summary, our study demonstrated that serum corin levels were decreased in CHF patients and inversely correlated with the incidence of CHF.

\section{MATERIALS AND METHODS}

\section{Study population}

We consecutively recruited $484 \mathrm{CHF}$ patients with different causes including ischemic, valvular, hypertensive, and cardiomyopathic etiologies between September 2015 and May 2017. The diagnosis of CHF was based on typical symptoms and signs and evidence of left ventricular enlargement and systolic functional impairment by echocardiography. A total of 484 control subjects were randomly selected from the healthy participants. This study was approved by the ethics committee of Soochow University and written informed consents were obtained from all participants.

\section{Clinical and biochemical measurements}

The clinical and biochemical data of patients were obtained from medical records. Hypertension was defined as systolic blood pressure $\geq 140 \mathrm{mmHg}$ or diastolic blood pressure $\geq 90 \mathrm{mmHg}$ or receiving antihypertensive therapy. Diabetes was defined as fasting glucose $\geq 7.0$ $\mathrm{mmol} / \mathrm{L}$ or 2 -hour postprandial blood glucose $\geq 11.1$ $\mathrm{mmol} / \mathrm{L}$ or use of antidiabetic agents. Hyperlipidemia was defined as triglyceride concentration $>1.7 \mathrm{mmol} / \mathrm{L}$ or total cholesterol concentration $>5.7 \mathrm{mmol} / \mathrm{L}$ or use of lipid-regulating drugs. The estimated glomerular filtration rate (eGFR) was calculated using the MDRD study equation, taking into account gender, age, race, and serum creatinine. Serum levels of corin and N-terminal pro-brain natriuretic peptide (NT-proBNP) were measured using enzyme-linked immunosorbent assay kits (R\&D Systems, Minneapolis, USA; Roche Diagnostics, Mannheim, Germany) according to the manufacturer's instructions. 


\section{Statistical analysis}

Data are presented as mean \pm SD or percentages. All statistical analyses were performed using SPSS software. Continuous variables were analyzed by Student's t test, while categorical variables were compared by $\chi^{2}$ test. Odds ratio (OR) and $95 \%$ confidence interval (CI) were calculated to determine the association between serum corin and CHF risk. Multiple logistic regression analysis was conducted to adjust for hypertension, diabetes, eGFR and NT-proBNP. A $P$ value $<0.05$ was considered statistically significant in this study.

\section{CONFLICTS OF INTEREST}

The authors declare no potential conflicts of interest.

\section{FUNDING}

This work was financially supported by the National Natural Science Foundation of China (81770370, 81700737, 81400292).

\section{REFERENCES}

1. Zhou Y, Wu Q. Corin in natriuretic peptide processing and hypertension. Curr Hypertens Rep. 2014; 16:415.

2. Chan JC, Knudson O, Wu F, Morser J, Dole WP, Wu Q. Hypertension in mice lacking the proatrial natriuretic peptide convertase corin. Proc Natl Acad Sci U S A. 2005; 102:785-90.
3. Gladysheva IP, Wang D, McNamee RA, Houng AK, Mohamad AA, Fan TM, Reed GL. Corin overexpression improves cardiac function, heart failure, and survival in mice with dilated cardiomyopathy. Hypertension. 2013; 61:327-32.

4. Zhang SM, Shen JX, Li H, Zhao P, Xu G, Chen JC. Association between serum corin levels and risk of acute myocardial infarction. Clin Chim Acta. 2016; 452:134-7.

5. Peng H, Zhu F, Shi J, Han X, Zhou D, Liu Y, Zhi Z, Zhang F, Shen Y, Ma J, Song Y, Hu W. Serum soluble corin is decreased in stroke. Stroke. 2015; 46:1758-63.

6. Kurrelmeyer K, Kalra D, Bozkurt B, Wang F, Dibbs Z, Seta Y, Baumgarten G, Engle D, Sivasubramanian N, Mann DL. Cardiac remodeling as a consequence and cause of progressive heart failure. Clin Cardiol. 1998; 21:I14-9.

7. Yan W, Sheng N, Seto M, Morser J, Wu Q. Corin, a mosaic transmembrane serine protease encoded by a novel cDNA from human heart. J Biol Chem. 1999; 274:14926-35.

8. Daniels LB, Maisel AS. Natriuretic peptides. J Am Coll Cardiol. 2007; 50:2357-68.

9. Zhou X, Chen J, Zhang Q, Shao J, Du K, Xu X, Kong Y. Prognostic value of plasma soluble corin in patients with acute myocardial infarction. J Am Coll Cardiol. 2016; 67:2008-14.

10. Zhou X, Chen JC, Liu Y, Yang H, Du K, Kong Y, Xu XH. Plasma corin as a predictor of cardiovascular events in patients with chronic heart failure. JACC Heart Fail. 2016; 4:664-9.

11. Dong N, Chen S, Yang J, He L, Liu P, Zheng D, Li L, Zhou Y, Ruan C, Plow E, Wu Q. Plasma soluble corin in patients with heart failure. Circ Heart Fail. 2010; 3:207-11. 